\title{
PEMBUATAN HOMEPAGE WAP
}

\section{MAKING WAP HOMEPAGE}

\author{
Adi Wibowo, Kolis Setyoningsih, Ir. Nanang Syahroni \\ Jurusan Teknik Telekomunikasi, Politeknik Elektronika Negeri Surabaya \\ Institut teknologi Sepuluh Nopember \\ Kampus ITS, Keputih Sukolilo, Surabaya 60111 \\ Telp. (+62)-31-5947280 Fax. (+62)-31-5946114 \\ Email : adin_boywo@yahoo.com; olis_smile@yahoo.com
}

\begin{abstract}
ABSTRAK
Dewasa ini penggunaan handphone semakin banyak, sehingga operator handphone menambah layanan dari handphone seperti SMS ( Short Message System ), e-mail, dan browsing internet dengan menggunakan teknologi WAP (Wireless Application Protocol ). Dan proyek akhir "Pembuatan Homepage WAP" dikerjakan untuk membuat suatu layanan informasi tentang Politeknik Elektronika Negeri Surabaya yang dapat diakses melalui handphone yang memiliki fasilitas WAP.

WAP dilengkapi standart universal yang memudahkan pemakainya mengakses web yang sudah didesain khusus untuk layanan informasi dan aplikasi pada komunikasi bergerak dengan menggunakan bahasa pemrograman WML ( Wireless Markup Language ). Dan dengan dilengkapi layanan WAP Phone akan memudahkan pemakai mengakses informasi mengenai Politeknik Elektronika Negeri Surabaya secara cepat, mudah, kapan saja, dan dimana saja melalui handphone WAP.
\end{abstract}

Kata Kunci : WAP, Internet, Handphone, WML.

\begin{abstract}
Recently many peoples using mobile phone ( handphone ), so the mobile operator increasing the service of mobile phone like SMS ( Short Message System ), e-mail, and internet browsing using WAP ( Wireless Appliation Protocol ) technology. And final project of " Making WAP Homepage " are to make an information service about Politeknik Elektronika Negeri Surabaya that could be acces by mobile phone that have WAP facilities.

WAP completed of universal standard can easily users to acces web designed, esspecially for information and application on mobile communication using WML ( Wireless Markup Language ) programming. And using WAP Phone service make users can acces information about Politeknik Elektronika Negeri Surabaya faster, easily, anytime, and everywhere using WAP devices.
\end{abstract}

Key word : WAP, Internet,Handphone, WML.

\section{PENDAHULUAN}

Maraknya penggunaan handphone mendorong hadirnya layanan handphone berupa SMS (Short Message Service), e-mail, dan browsing internet dengan teknologi WAP (Wireless Application Protocol) phone. Handphone merupakan salah satu alat komunikasi yang banyak dipakai dalam dunia modern. Dengan dilengkapi layanan WAP phone, seorang pemakai dapat mengakses berbagai informasi langsung dari internet. Tentu saja 
hanya Web site yang menyediakan format data yang dapat diakses lewat handphone. Dalam waktu dekat WAP phone menjadi bagian dari gaya hidup modern.

WAP merupakan gerbang menuju dunia baru. WAP dilengkapi standart universal yang memudahkan pemakainya mengakses Web yang sudah didesain khusus untuk layanan informasi dan aplikasi pada perangkat komunikasi bergerak separti handphone. Sehingga proyek akhir Pembuatan Homepage WAP diajukan untuk memperkenalkan / memberitahu informasi mengenai Politeknik pada masyarakat umum dengan menggunakan akses internet melalui handphone yang memiliki fasilitas WAP.

2. PERENCANAAN DAN

2.1. Perencanaan

2.2.1. Blok Diagram

Secara umum blok diagram dari suatu layanan WAP adalah sebagai berikut:

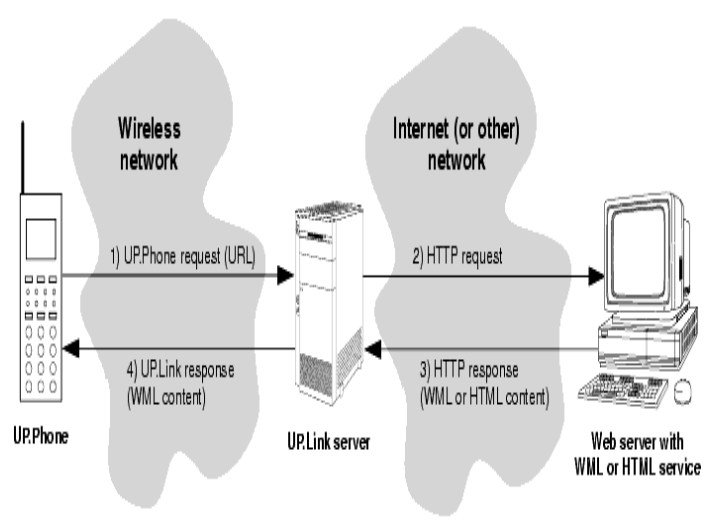

gambar 3.1 Blok diagaram layanan WAP

\subsubsection{Prinsip kerja dari suatu layanan WAP seperti diatas adalah :}

Suatu WAP DEVICE memiliki kemampuan untuk mengirimkan suatu permintaan (URL) pada jaringan wireless menuju WAP GATEWAY (UP.Link Server). WAP GATEWAY (UP.Link Server) akan mengkonversikan permintaan (URL) tersebut kedalam bentuk permintaan Hypertext Transport Protocol (HTTP) dan mengirimkannya melalui internet. Ketika permintaan tersebut mendapat respon dari server, maka server akan mengirim informasi yang diinginkan ke WAP DEVICES melalui WAP GATEWAY (UP.Link Server).

\subsection{Pembuatan} antara lain :

Ada beberapa tahap yang dapat dilakukan untuk membuat suatu homepage WAP

\subsubsection{Pembuatan program WML}

Suatu pemrograman dan desain dari site yang akan dibuat dengan menggunakan bahasa pemrograman Wireless Markup Language (WML). Untuk menyususn suatu halaman wml haruslah diawali dengan baris dari XML yang berfungsi sebagai header, seperti contoh berikut:

$<$ ? $\mathrm{xml}$ version="1.0"? $>$

$<$ ?DOCTYPE wml PUBLIC"'-??WAPFORUM//

DTD WML 1.1//EN" 


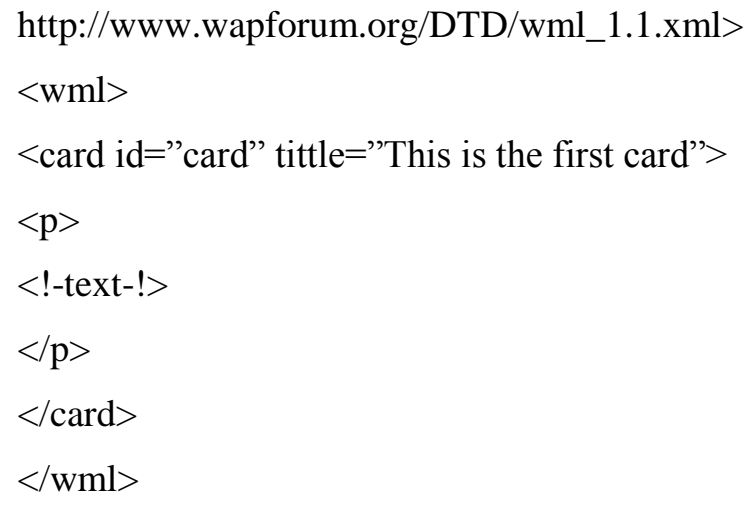

\subsubsection{Emulator/Simulator}

Untuk mengetahui hasil sementara dari program WML yang telah dibuat dilakukan dengan cara mensimulasikan ke suatu Emulator / Simulator WAP Browser sebagai pengganti sebelum ditampilkan pada WAP Devices (WAP Phone) sesungguhnya.

Didalam Emulator / Simulator WAP Browser ini, memiliki kemampuan dan fungsifungsi yang hampir sama dengan kemampuan dan fungsi-fungsi yang dimiliki WAP Phone. Hanya saja kemampuan dan fungsi yang dimiliki oleh Emulator / Simulator WAP Browser antara satu dengan lainnya berbeda-beda dan tidak semua Emulator / Simulator WAP Browser mampu mendukung bahasa-bahasa pemrograman wireless yang digunakan seperti halnya WML, CGI, java,dll. Karena dalam proyek akhir ini, bahasa pemrograman yang digunakan merupakan bahasa WML maka hanya beberapa Emulator / Simulator yang dapat digunakan seperti Emulator M3Gate, Emulator pada Nokia Toolkit atau Simulator WAP dari ERICSSON.

\subsubsection{Upload file}

Agar suatu file yang telah dibuat dapat ditampilkan dalam WAP Devices maka file yang telah dibuat haruslah berada dalam suatu server. Dengan kemudahan yang didapatkan dari internet, maka untuk proyek akhir ini dikerjakan dengan memanfaatkan fasilitas FREE WAP SERVER yang banyak dijumpai pada situs-situs di internet, tapi tidak semua FREE WAP SERVER yang ada di internet mendukung bahasa pemrograman yang digunakan (dalam hal ini digunakan bahasa pemrograman Wireless Application Protocol /WML).

Pada FREE WAP SERVER biasanya menyediakan didalamnya tersedia free disk space WAP Server yang dapat dimanfaatkan untuk meng-upload file-file wml yang di inginkan agar file-file wml yang kita upload dapat berinteraksi dengan dunia wireless.

\section{ANALISA}

\subsection{Setting Layanan WAP}

Pada setiap WAP Phone yang akan digunakan untuk mengakses internet melalui fasilitas WAP, terlebih dahulu untuk mengaktifkan layanan WAP pada WAP Phone sesuai dengan operator ( SIM Card ) yang digunakan. Karena tidak semua operator memiliki ketentuan yang sama.

Terlebih dahulu hubungi operator yang digunakan untuk meminta pengaktifan penggunaan dari layanan WAP pada SIM Card. Kemudian operator akan mengaktifkan layanan WAP dari WAP Phone yang dinginkan dengan memberikan IP Address dan Gateway yang dapat digunakan untuk dapat mengakses internet.

Suatu handphone yang memiliki fasilitas WAP terlebih dahulu di-setting untuk dapat mengakses alamat URL tersebut. Dimana tiap-tiap handphone memiliki setting yang berbeda-beda tergantung dari merk dan type dari handphone yang digunakan serta operator layanan seluler yang digunakan (kartu prabayar yang digunakan). Dalam Proyek 
Akhir ini, kita menggunakan handphone dengan merk Ericsson type T 20s dan jasa excelmindo (Pro XL) untuk operator layanan seluler (kartu prabayar) yang digunakan.

\subsection{Tampilan pada layar handphone}

Dari diagram site yang terlampir akan didapatkan suatu tampilan awal dari wap site yang dibuat seperti berikut ini :

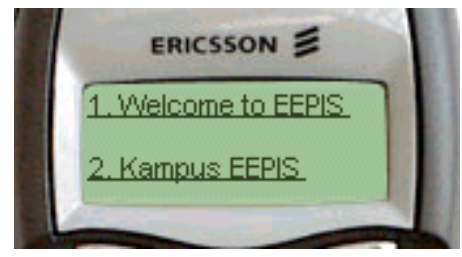

Gambar3.2.2. Tampilan Awal

Menu - menu yang dapat ditampilkan pada layar handphone tersebut memiliki link yang akan terhubung dengan informasi - informasi dari menu. Ketika user mengakses / mengklik dari salah satu menu yang diinginkan maka user akan memperoleh informasi tentang menu tersebut.

\section{KESIMPULAN DAN SARAN}

\subsection{KESIMPULAN}

Dengan adanya homepage ini diharapkan dapat mempermudah masyarakat dalam mengakses / mencari informasi mengenai Politeknik Elektonika Negeri Surabaya secara cepat, mudah, dimana saja, dan kapan saja dengan menggunakan akses internet melalui handphone yang memiliki fasilitas WAP.

\subsection{SARAN DAN PERBAIKAN}

Pada aplikasi ini masih terdapat banyak kekurangan yang dapat dilakukan perbaikan pada masa mendatang yaitu:

- Sifat homepage yang statis dan kurang interaktif bagi user, sehingga diharapkan untuk masa-masa mendatang dapat dibuat suatu homepage yang lebih interaktif dan tidak statis.

- Pemakaian fasilitas Free WAP Server yang mengakibatkan kesulitan untuk membuat suatu layana database dari homepage. Dan diharapakan pada masa mendatang dapat dibuat suatu homepage dengan WAP Server sendiri sehingga memungkinkan adanya suatu database dari homepage tersebut.

\section{DAFTAR PUSTAKA}

1. Steven Vaughan-Nichols, Rob Tidrow, Loren Buhle, Jason Kuffer, Noel Taylor; Yang Perlu Anda Ketahui Tentang Workd Wide Web; ANDI Yogyakakrta; 2000.

2. MIKRODATA Volume 6 seri 15; WAP Akses Internet Lewat Handphone; Elex Media Komputindo; 2000.

3. MIKRODATA Volume 7 seri 15; WAP Site Programming; Elex Media Komputindo; 2000.

\section{DAFTAR WEBSITE}

1. http://www.wannawap.com/

2. http://wap.eponsel.com/

3. http://www.yahoo.com/ 

4. http://www.gogle.com/
5. http://www.ericsson.se/
6. http://www.wapresources.com/
7. http://www.wapforum.com/ 